\title{
An Analysis on the Coordination Development of Low-carbon Economy in Mongolia
}

\author{
Nomin-Erdene Chimeddorj ${ }^{1}$ \\ ${ }^{1}$ School of Management, Shanghai University Shanghai, Shanghai, China \\ Correspondence: Nomin-Erdene Chimeddorj, School of Management, Shanghai University, Shanghai, Baoshan \\ district, Shangda Road, No.99, China. Tel: 0086-186-2162-8728. E-mail: nomiko_gogogo@yahoo.com
}

Received: April 30, 2015

Accepted: June 10, 2015

Online Published: September 30, 2015

doi:10.5539/eer.v5n2p22

URL: http://dx.doi.org/10.5539/eer.v5n2p22

\begin{abstract}
Currently, the global economic growth model is based on the input of resources, especially the input of energy. Throughout the energy structures all over the world, mostly coal, oil, natural gas and other high-carbon fossil fuels, and those high-carbon fossil fuels have become the main source of atmospheric carbon dioxide and other greenhouse gases. Economic growth and energy consumption, there should be causal relationship between economic growth and carbon dioxide emissions, the economic growth model can get rid of the fossil energy constraints, whereas carbon dioxide emissions can be disconnected from the economic growth, to cope with these problems facing the development of low-carbon economy in Mongolia. The research makes use of time-series model to test the causal relationship between economic growth and energy consumption, economic growth and carbon dioxide emissions as well as between energy consumption and carbon dioxide emissions.
\end{abstract}

Keywords: Economic Growth, Energy Consumption, Carbon Emissions, Co-integration Analysis, Granger Causality Test

\section{Introduction}

Currently, the energy structure of Mongolia is dominated by coal, while other renewable clean energy such as solar energy and wind energy accounts for only a very small proportion, so high-carbon fossil energy sources decide the "High-Carbon Model" of Mongolia's economic development(Government of Mongolia, 2011). In recent years, sustained and rapid economic growth of Mongolia has changed its national image and improved people's lives, but the country has paid an expensive price at the resources and environment, destroying the coordinative relationship among economy, resources and environment. Resources and environment have more and more become there straining factor to the economic development and gradually the primary factor affecting the economic development and social progress of Mongolia (Batjargal, Mijiddorj \& Ulziisaihan, 1998, p.120-140). Therefore this economic and social development model is not sustainable, which presents a violation of the sustainable and harmonious development proposed by the government. Therefore, it has become urgent to adopt strategic choice to develop low-carbon economy, transform economic growth mode, look for a breakthrough in energy conservation and emission reduction, and promote the economic development of Mongolia to transform from high-carbon economy to low-carbon and carbon-free economy, so as to achieve scientific, harmonious and green development. Low-carbon economy is developed by closely connecting economic development and carbon emissions formed during the industrial civilization period so that the economic development and the accumulation of wealth shall no longer be achieved through the burning of fossil fuels. As we can see, when the global economic growth is slow, in stagnation or even downturn, with the increasing unemployment and other economic and social crisis, low-carbon green industries, such as the new energy and energy conservation emissions reduction, rose magnificently, becoming the point of growth of economic development in all countries, showing very strong vitality, and solving social problems such as employment and reassignmentas an effective prescription. Mongolia should include low-carbon economy into the national development strategies as soon as possible, changing the macro-economic growth mode through the will of the country, promoting low-carbon production and low-carbon lifestyle, guiding the entire social production and life into low-carbon path, so as to promote a comprehensive and sustainable development of ecology, economy and society as a whole entity. 


\section{Methodology}

\subsection{Time Series Model}

\subsubsection{Establishment of Time Series model}

Autoregressive integrated moving average (ARIMA), also known as Box-Jenkins model, or referred to as BJ model in short, is a time-series forecasting method named after the well-known American statistician Box and British statistician Jenkins.

Stochastic time series model refers to the model established only applying its past values and random disturbance, its general form is

$$
\begin{gathered}
X_{t}=Y\left(X_{t-1}, X_{t-2}, \ldots, \mu_{t}\right) \\
X_{t}=\varphi_{1} X_{t-1}+\varphi_{2} X_{t-2}+\cdots+\varphi_{p} X_{t-p}+\mu_{t}
\end{gathered}
$$

If the random error term $\mu_{\mathrm{t}}$ is white noise, i.e. zero mean, and the variance being the random series with stable a constant $\mu_{\mathrm{t}}=\varepsilon_{\mathrm{t}}$, it is called the formula (2) as pure AR (p) process, denoted as:

$$
X_{t}=\varphi_{1} X_{t-1}+\varphi_{2} X_{t-2}+\cdots+\varphi_{p} X_{t-p}+\varepsilon_{t}
$$

If the random error term is not white noise, it is generally considered as a moving average process of lag $\mathrm{q}$ MA(q), denoted as:

$$
\mu_{t}=\varepsilon_{t}-\theta_{1} \varepsilon_{t-1}-\theta_{2} \varepsilon_{t-2-} \ldots-\theta_{q} \varepsilon_{t-q}
$$

Combine the pure AR (p) with the pure MA (q) to get a general ARMA (p, q):

$$
X_{t}=\varphi_{1} X_{t-1}+\varphi_{2} X_{t-2}+\cdots+\varphi_{p} X_{t-p}+\varepsilon_{t}-\theta_{1} \varepsilon_{t-1}-\theta_{2} \varepsilon_{t-2-} \cdots-\theta_{q} \varepsilon_{t-q}
$$

Formula (5) represents a random time series generated by an auto-regressive moving average process, i.e., the series being explained by its own past or lagged values and random disturbance. If the series is stationary, i.e., it failing to act and vary over time, you can also predict the future by the past behaviour of the series.

\subsubsection{Application of Time Series Model}

In the use of time series analysis, we need to ensure stationary series. If the probability distribution function of a time series does not vary over time, and the expected value, variance and auto covariance are constants, the time series is stationary. For non-stationary time series, differential or logarithmic transformation can be performed on the series, and then analyze it when it becomes stationary.

In general, time series analysis is mainly used in the system description and analysis, decision-making and control and other aspects. According to the observation values by the system, by adjusting the input variables, compare the influence of the curve fitting to the system to understand the mechanism of production of a given time series. You can also predict the future, and make necessary controls when the system runs away from the goal.

\subsection{Stationary Test of Time Series}

\subsubsection{Stationarity of Time Series}

The so-called stationarity of time series refers to the statistical regularities that the time series will not varywith the passage of time. In other words, the characteristics of the random process of generating a variable time series data do not varyover time. If the characteristics of the random process varyover time, then the process is non-stationary. The basic use of time series analysis is to predict the future according to the past, i.e. using the variations in one time series to explain the variations in another time series, therefore, it must be assumed that the development process in the past is what the future should be, also referred to as stationarity assumption. Stationarity of stochastic time series model can be judged by that of the random time series it generates. If the time series generated by a Lag P autoregressive model AR (p) is stationary, the AR (p) model is stationary, otherwise, the AR (p) model is non-stationary (Sun, 2005).

Amusing that a time series is generated by a random process, i.e.,each value of the time series assumed $\left\{\mathrm{X}_{\mathrm{t}}\right\}(\mathrm{t}=$ $1,2, \ldots)$ being obtained randomly, if the time series $\left\{X_{t}\right\}(t=1,2, \ldots)$ satisfies the following conditions:

I. The mean $E\left(X_{t}\right)=\mu$ is a constant independent of time $\mathrm{t}$;

II. Variance $\operatorname{Var}\left(X_{t}\right)=E\left(X_{t}-\mu\right)^{2}=\sigma^{2}$ is a constant independent of time t;

III. Covariance $\operatorname{Cov}\left(X_{t}, X_{t+k}\right)=E\left[\left(X_{t}-\mu\right)\left(X_{t+k}-\mu\right)\right]=\gamma_{k}$ is related to the time interval $\mathrm{k}$, which is a 
constant independent of time $t$.

It can be said that the random time series is stationary, and the stochastic process is a stationary random process.

If the random time series is not stationary, and if the average is non-stationary series, differential or seasonal differential transformation can be used to change the stationarity of the original series. If it is variance of non-stationary series, logarithmic transformation, square root transformation etc. can be used to process the data, so as to achieve a stationary series to facilitate analysis.

\subsubsection{Unit Root Test on Stationarity}

In the real economy, most economic variables are non-stationary, and in econometric modelling process, economic time series is usually assumed to be stationary, so that the regression analysis may lead to a false regression or spurious regression that makes the regression results invalid. So before the co-integration analysis of the variables, the time series data must undergo stationary test. Unit root test is the test of the stationarity of time series, and the commonly used test methods include Dickey-Fuller Test, Augmented Dickey Fuller and Phillips-Perron Test. The ADF presented by Fuller and Dickey and extended by Fuller and Dickey later is the most important and most commonly used test method (Dickey \& Fuller, 1979).

The inspection equation of $\mathrm{ADF}$ is:

Model 1 (impermanence number and time trend):

$$
\Delta X_{t}=\delta X_{t-1}+\sum_{i=1}^{m} \beta_{i} \Delta X_{t-i}+\varepsilon
$$

Model 2 (with the constant term, no time trend):

$$
\Delta X_{t}=\alpha+\delta X_{t-1}+\sum_{i=1}^{m} \beta_{i} \Delta X_{t-i}+\varepsilon_{t}
$$

Model 3 (with constant term and time trend):

$$
\Delta X_{t}=\alpha+\beta t+\delta X_{t-1}+\sum_{i=1}^{m} \beta_{i} \Delta X_{t-i}+\varepsilon_{t}
$$

Where: $\mathrm{t}$ is the time variable, $\mathrm{m}=1,2,3$, the original hypothesis $\mathrm{H} 0: \delta=0$, namely the existence of a unit root. The actual test generally starts from Model 3 (with constant term and time trend), then the models 2 and 1 . When the test rejects the original hypothesis, the original series does not indicate the presence of a unit root. When it is a stationary series, the test will end.

In the ADF root test, whether to add constant term or the time trend in the model shall be decided according to the time series diagram generated. If the time series contains the constant term, the mean of time series tested shall not be zero, and whether constant term shall be added is decided by observing whether the series diagram varies randomly at the position with a zero mean; in the regression test, the linear trend means the original series has a time trend, and whether to add the time trend is decided by observing whether the time series diagram varies over time.

\subsection{Co-Integration Test of Time Series}

Formally presented by Granger and Engle in the late 1980s, co-integration theory determines the theoretical relationship between the variables and variables included in the model based on the relationship shown in data of economic variables. According to co-integration theory, if a linear combination of a non-stationary series may exhibit stationarity, there will be long-term stable relationship between the variables

\subsubsection{Integration}

Randoming Walk Series $X_{t}=X_{t-1}+\mu_{t}$, its equivalent deformation after difference is given as

$$
\Delta X_{t}=X_{t}-X_{t-1}=\mu_{t}
$$

Where $\mu_{\mathrm{t}}$ is white noise, so the series $\left\{\Delta X_{t}\right\}$ after the difference is stationary. If a time series after one difference turns stationary, it is integration of lag 1 , denoted as $X_{t} \sim I(1)$. If the series $\Delta X_{t}$ after lag d difference $\Delta^{d} X_{t}=$ $\Delta\left(\Delta^{d-1} X_{t}\right)$ is stationary, the time series is integration of lag d, denoted as $\mathrm{X}_{\mathrm{t}} \sim \mathrm{I}(\mathrm{d})$.

\subsubsection{Co-Integration}

Economic theory suggests that, economic variables have their own long-term fluctuation rules, if the economic variables are co-integrated, the co-existence of long-term stable equilibrium relationship in the whole co-integrated economic variables. If the variable is disturbed at a certain period and deviates from the long-run equilibrium point, this balancing mechanism will be adjusted in the next period to get back to equilibrium.

If two variables are integrated, and only when they are at the same integrated lag, there may be co-integration, if they are at different integrated lags, there will be no co-integration. If two or more variables are at different 
integrated orders, they may possibly constitute a low-order integrated variable in the form of linear combination. If the two time series are $Y_{t} \sim I(d)$ and $X_{t} \sim I(d)$, generate linear regression equation through OLS.

$$
Y_{t}=\alpha+\beta X_{t}+\varepsilon_{t}
$$

As for the stationarity of residuals $\varepsilon_{t}$ in inspection formula (10), if $\varepsilon_{t}$ is stationary, the two series have co-integration relationship; if $\varepsilon_{t}$ is not stationary, no co-integration relationship exists. The co-integration test on variables can effectively avoid spurious regression in numerical analysis.

\subsection{Granger Test of Causality on Time Series}

The causal relationship is the dependence between variables. The outcome variable is decided by the causal variable. The changes in causal variable lead to the changes in outcome variable. Granger from the perspective of prediction proposed a test program, called Granger causality test (Dan, 2002).

For two variables $\mathrm{Y}$ and $\mathrm{X}$, Granger causality test requires estimating the following regressions:

$$
\begin{aligned}
& Y_{t}=\sum_{i=1}^{m} \alpha_{i} X_{t-i}+\sum_{i=1}^{m} \beta_{i} Y_{t-i}+\mu_{1 t} \\
& X_{t}=\sum_{i=1}^{m} \lambda_{i} Y_{t-i}+\sum_{i=1}^{m} \delta_{i} X_{t-i}+\mu_{2 t}
\end{aligned}
$$

(1) $X$ has individual impact on $Y$, as shown in formula (11), the overall parameter before each lagged variable of $\mathrm{X}$ is not zero, and the overall parameter before each lagged variable of $\mathrm{Y}$ in formula (12) is zero;

(2) $\mathrm{Y}$ has individual impact $\mathrm{X}$, as shown in formula (12), the overall parameter before each lagged variable of $\mathrm{Y}$ is not zero, and the overall parameter before each lagged variable of $\mathrm{X}$ in formula (11) is zero;

(3) There is bidirectional impact between $\mathrm{Y}$ and $\mathrm{X}$, The overall parameter before each lagged variable of $\mathrm{Y}$ and $\mathrm{X}$ is not zero;

(4) There is not impact between $Y$ and $X$. The overall parameter before each lagged variable of $Y$ and $X$ is zero.

Granger causality test is done by restrained $\mathrm{F}$ test. To testify the hypothesis that $\mathrm{X}$ is the cause of $\mathrm{Y}$, based on the hypothesis in formula (11) that the overall parameter $\alpha_{\mathrm{i}}$ before the lagged variables of $\mathrm{X}$ is zero, restrained regressions without lagged variables of $\mathrm{X}$ are performed respectively to get the restrained residual squares and RSSR as well as the unrestrained regressions including the lagged variables of $\mathrm{X}$, and thus getting unrestrained residual squares and RSSU to calculate F statistic:

$$
F=\frac{\left(R S S_{R}-R S S_{U}\right) / q}{R S S_{U} /(n-k)}
$$

$\mathrm{N}$ is the sample size, $\mathrm{q}$ is the number of the lagged variables of $\mathrm{X}$, i.e., the number of estimated parameters in restrained regression equations, $\mathrm{k}$ is the number of parameters to be estimated in unrestrained regressions.

If $\mathrm{F}$ value calculated on the selected significance level $\alpha$ exceeds the critical value $\mathrm{F}_{\alpha}(\mathrm{q}, \mathrm{n}-\mathrm{k})$, the null hypothesis is rejected, so $\mathrm{X}$ is the case of $\mathrm{Y}$.

It should be noted that, Granger causality test sometimes is very sensitive to the choice of the lag length, and different lag lengths may lead to a completely different test result. Thus, in general, tests on different lag lengths are performed to verify that lag length of related series do not exist in random disturbance in the model to select lag length.

\section{Empirical Analysis}

\subsection{Data Selection}

The research applies the carbon dioxide emissions of Mongolia from 1990 to 2012 provided by Energy Information Administration in the data of annual $\mathrm{CO}_{2}$ emissions of all countries and the GDP and energy consumption data from 1990 to 2012 released by World Bank statistics. The co-integration and causality test

\begin{tabular}{|c|c|c|c|}
\hline Year & GDP (million USD) & ENE (Mtoe) & $\mathrm{CO}_{2}$ Emissions (Mt) \\
\hline 1990 & 1847.93 & 3.408 & 12.655 \\
\hline 1991 & 1687.28 & 3.816 & 14.417 \\
\hline 1992 & 1531.10 & 3.340 & 12.596 \\
\hline
\end{tabular}
herein are carried out through Eview7. The GDP is the constant value after the elimination of corresponding price level effect.

Table 1. GDP, Energy consumption and Carbon dioxide emission values of Mongolia from 1990 to 2012 


\begin{tabular}{cccc}
\hline 1993 & 1482.58 & 3.124 & 11.633 \\
1994 & 1514.22 & 2.701 & 10.116 \\
1995 & 1610.78 & 2.695 & 10.054 \\
1996 & 1646.80 & 2.270 & 8.503 \\
1997 & 1710.95 & 2.223 & 8.334 \\
1998 & 1768.09 & 2.241 & 8.363 \\
1999 & 1822.38 & 2.244 & 8.427 \\
2000 & 1843.27 & 2.397 & 8.813 \\
2001 & 1897.69 & 2.415 & 8.798 \\
2002 & 1987.51 & 2.586 & 9.397 \\
2003 & 2126.73 & 2.525 & 9.101 \\
2004 & 2352.70 & 2.601 & 9.350 \\
2005 & 2523.36 & 2.625 & 9.479 \\
2006 & 2739.26 & 2.925 & 10.488 \\
2007 & 3019.98 & 3.114 & 11.056 \\
2008 & 3288.77 & 3.156 & 11.078 \\
2009 & 3247.05 & 3.252 & 11.645 \\
2010 & 3453.73 & 3.454 & 12.527 \\
2011 & 4058.61 & 3.597 & 12.985 \\
2012 & 4557.14 & 3.943 & 14.216 \\
\hline
\end{tabular}

source: World Bank, EIA

\subsection{Data Analysis}

\subsubsection{Stationary Analysis}

According to the ARMA (p, q) in formula(5) and the three forms in formulas (6), (7) and (8), carry out stationarity test on GDP, ENE and $\mathrm{CO}_{2}$ emissions in Table 1,

Table 2. ADF Unit Root Test Result of GDP, $\mathrm{CO}_{2}$ and ENE

\begin{tabular}{lcccccc}
\hline Variables & Test form & ADF value & $1 \%$ level & $5 \%$ level & $10 \%$ level & Prob.* \\
\hline GDP & $(\mathrm{C}, 0,1)$ & 3.490986 & -3.808546 & -3.020686 & -2.650413 & -2.650413 \\
ENE & $(\mathrm{C}, 0,1)$ & -0.851221 & -3.808546 & -3.020686 & -2.650413 & 0.7820 \\
$\mathrm{CO}_{2}$ & $(\mathrm{C}, 0,1)$ & -0.924708 & -3.808546 & -3.020686 & -2.650413 & 0.7585 \\
$\mathrm{D}(\mathrm{GDP})$ & $(\mathrm{C}, 0,2)$ & -4.433862 & -4.616209 & -3.710482 & -3.297799 & 0.0139 \\
$\mathrm{D}(\mathrm{ENE})$ & $(\mathrm{C}, 0,2)$ & -8.560345 & -4.467895 & -3.644963 & -3.261452 & 0.0000 \\
$\mathrm{D}\left(\mathrm{CO}_{2}\right)$ & $(\mathrm{C}, 0,2)$ & -9.437952 & -4.467895 & -3.644963 & -3.261452 & 0.0000 \\
$\mathrm{D}(\mathrm{GDP}, 2)$ & $(\mathrm{C}, 0,1)$ & -3.263814 & -3.920350 & -3.065585 & -2.673459 & 0.0348 \\
$\mathrm{D}(\mathrm{ENE}, 2)$ & $(\mathrm{C}, 0,1)$ & -12.09087 & -3.808546 & -3.020686 & -2.650413 & 0.0000 \\
$\mathrm{D}\left(\mathrm{CO}_{2}, 2\right)$ & $(\mathrm{C}, 0,1)$ & -11.67122 & -3.808546 & -3.020686 & -2.650413 & 0.0000 \\
\hline
\end{tabular}

Note. $(\mathrm{C}, \mathrm{T}, \mathrm{K})$ represent the constant, time trend and lagging rank figure in the model. $\mathrm{D}(\mathrm{x})$ :first-order difference, $\mathrm{D}(\mathrm{x}, 2)$ : second-order difference.

The results of Table 2 show that, although the variables GDP, ENE, and $\mathrm{CO}_{2}$ all have shown non-stationary nature, their first-order differences and second-order differences $\mathrm{D}(\mathrm{GDP}), \mathrm{D}(\mathrm{ENE}), \mathrm{D}\left(\mathrm{CO}_{2}\right), \mathrm{D}(\mathrm{GDP}, 2)$, $\mathrm{D}(\mathrm{ENE}, 2)$ and $\mathrm{D}\left(\mathrm{CO}_{2}, 2\right)$ all have rejected the null hypothesis of existence of unit root at $5 \%$ significance level, they all belong to the first-order stationary sequences. Hence, co-integration analysis can be conducted on the difference of the original data.

\subsubsection{Co-integration Analysis}

To investigate whether there exists long-term stable equilibrium relation between GDP and ENE, GDP and $\mathrm{CO}_{2}$ or ENE and $\mathrm{CO}_{2}$, that is, whether these variables are co-integrated, Johansen maximum likelihood estimation is used to test the co-integration relation of each variable. Test results are shown in Table 3. 
Table 3. Johansen Co-integration Analysis table

\begin{tabular}{cccccc}
\hline Variables & $\begin{array}{c}\text { Co-integration } \\
\text { equation }\end{array}$ & Eigenvalue & $\begin{array}{c}\text { Trace } \\
\text { statistic }\end{array}$ & $\begin{array}{c}0.05 \\
\text { Critical Value }\end{array}$ & Prob.** \\
\hline GDP ENE & $\mathrm{N}=0^{*}$ & 0.662786 & 25.79797 & 15.49471 & 0.0010 \\
& $\mathrm{~N} \leq 1$ & 0.131891 & 2.970192 & 3.841466 & 0.0848
\end{tabular}

Trace test indicates 1 co-integrating eqn(s) at the 0.05 level

Max-eigenvalue test indicates 1 co-integrating eqn(s) at the 0.05 level

$\begin{array}{llllll}\mathrm{GDP} \mathrm{CO}_{2} & \mathrm{~N}=0 * & 0.714124 & 28.96681 & 15.49471 & 0.0003 \\ & \mathrm{~N}<1 & 0.119420 & 2.670673 & 3.841466 & 0.1022\end{array}$

Trace test indicates 1 co-integrating eqn(s) at the 0.05 level

Max-eigenvalue test indicates 1 co-integrating eqn(s) at the 0.05 level

$\begin{array}{llllll}\mathrm{ENE} \mathrm{CO}_{2} & \mathrm{~N}=0^{*} & 0.727014 & 27.81656 & 15.49471 & 0.0004 \\ & \mathrm{~N} \leq 1 & 0.025921 & 0.551530 & 3.841466 & 0.4577\end{array}$

Trace test indicates 1 co-integrating eqn(s) at the 0.05 level

Max-eigenvalue test indicates 1 co-integrating eqn(s) at the 0.05 level

From Table 3 we can see that, the null hypothesis with one co-integration equation is accepted at $5 \%$ significance level.

Therefore, at the 5\% significance level, there only exists a long-term equilibrium co-integration relationship between the each variables, this long-term equilibrium relationship can guarantee any short-term deviation of variables of returning to the long-run equilibrium state because of the co-integration relationship.

1) Error Correction Model

By conducting co-integration test on GDP and ENE, GDP and $\mathrm{CO}_{2}$. Construct single-element regression model by OLS

$$
\begin{gathered}
G D P=966.234496104 * E N E-464.447631718 \\
G D P=225.989288628 * C O_{2}-62.1856375286 \\
E N E=0.274139600961 * C_{2}-0.0107653596033
\end{gathered}
$$

Test the integrity of disequilibrium error sequence $\varepsilon_{1}$ of the GDP and DENE, the disequilibrium error sequence $\varepsilon_{2}$ of the GDP and $\mathrm{DCO}_{2}$ and the disequilibrium error sequence $\varepsilon_{3}$ of DENE and $\mathrm{DCO}_{2}$.

$$
\begin{aligned}
& \varepsilon_{1}=G D P-966.234496104 * E N E+464.447631718 \\
& \varepsilon_{2}=G D P-225.989288628 * C O_{2}+62.1856375286 \\
& \varepsilon_{3}=E N E-0.274139600961 * C O_{2}+0.0107653596033
\end{aligned}
$$

According to formula (17), (18) and (19), $\varepsilon 1, \varepsilon 2$ and $\varepsilon 3$ can be calculated respectively by using Software Eviews7.0, which are summarized in Table 4.

Table 4. Non equilibrium error sequences of $\varepsilon_{1}, \varepsilon_{2}$ and $\varepsilon_{3}$ ADF test results

\begin{tabular}{ccccccc}
\hline Variables & Test form & t-Statistic & $1 \%$ level & $5 \%$ level & $10 \%$ level & Prob.* \\
\hline$\varepsilon_{1}$ & $(\mathrm{C}, 0,1)$ & -4.454666 & -4.571559 & -3.690814 & -3.286909 & 0.0124 \\
$\varepsilon_{2}$ & $(\mathrm{C}, 0,1)$ & -5.045783 & -4.571559 & -3.690814 & -3.286909 & 0.0042 \\
$\varepsilon_{3}$ & $(\mathrm{C}, 0,1)$ & -1.081100 & -2.674290 & -1.957204 & -1.608175 & 0.2442 \\
\hline
\end{tabular}

As it can be seen from Table 4, the ADF values of disequilibrium error sequence $\varepsilon_{1}$ and $\varepsilon_{2}$ are -4.454666 and -5.045783 at $1 \%, 5 \%$ and $10 \%$ levels reject the null hypothesis respectively, thus they are stationary series. The $\mathrm{ADF}$ values of $\varepsilon_{3}$ is -1.081100 are greater than $1 \%, 5 \%$ and $10 \%$ levels, thus they accept the null hypothesis and shall be regarded as stationary sequence. Therefore, according to disequilibrium error sequence test results, the $\mathrm{ADF}$ values of GDP and ENE, GDP and $\mathrm{CO}_{2}$ all reject the null hypothesis, with co-integration relationship.

2) Granger Causality Test

According to formula (12), a new formula based on the original sequence (DGDP represents the increase of the 
GDP, DENE represents annual growth of ENE, and DCO2 represents annual growth of the amount of CO2) can be obtainded, and then perform Granger causality test on DGDP and DENE, DGDP and DCO2, DENE and DCO2 respectively, the following results can be got as shown in Table 5, Table 6 and Table 7 respectively.

Table 5. Granger Causality Test results of DGDP and DENE

\begin{tabular}{clcccc}
\hline Lags: & Null Hypothesis: & Obs & F-Statistic & Prob. & Conclusion \\
\hline 1 & D(ENE) does not Granger Cause D(GDP) & 21 & 0.17886 & 0.6774 & Accept \\
& D(GDP) does not Granger Cause D(ENE) & & 10.0266 & 0.0053 & Reject \\
2 & D(ENE) does not Granger Cause D(GDP) & 20 & 1.64046 & 0.2268 & Accept \\
& D(GDP) does not Granger Cause D(ENE) & & 2.27966 & 0.1366 & Accept \\
\hline
\end{tabular}

As it can be seen from Table 5, at Lags 1 and 2, in the Granger causality test on DGDP and DENE, the original hypothesis "D(GDP) does not Granger Cause $\mathrm{D}(\mathrm{ENE})$ " in Lag 1, P value is 0.0053 , it's considered to reject the former hypothesis that the GDP growth is the cause of the increase in energy consumption. For the original hypothesis "D(ENE) does not Granger Cause D(GDP)", P values in Lags 1 and 2 are 0.6774 and 0.2268 respectively, so it is considered to accept the original hypothesis that ENE is not cause of GDP, namely, the increase of energy consumption is cause of the changes and growth of GDP. In the current economic growth, economic growth may increase energy consumption, which is in line with the current energy-driven economic growth model.

Table 6. Granger Causality Test results of DGDP and $\mathrm{DCO}_{2}$

\begin{tabular}{cccccc}
\hline Lags: & Null Hypothesis: & Obs & F-Statistic & Prob. & Conclusion \\
\hline 1 & $\mathrm{D}\left(\mathrm{CO}_{2}\right)$ does not Granger Cause $\mathrm{D}(\mathrm{GDP})$ & 21 & 0.36907 & 0.5511 & Accept \\
& $\mathrm{D}(\mathrm{GDP})$ does not Granger Cause $\mathrm{D}\left(\mathrm{CO}_{2}\right)$ & & 10.5345 & 0.0045 & Reject \\
2 & $\mathrm{D}\left(\mathrm{CO}_{2}\right)$ does not Granger Cause $\mathrm{D}(\mathrm{GDP})$ & 20 & 2.74080 & 0.0967 & Accept \\
& $\mathrm{D}(\mathrm{GDP})$ does not Granger Cause $\mathrm{D}\left(\mathrm{CO}_{2}\right)$ & & 3.22170 & 0.0685 & Accept \\
\hline
\end{tabular}

As it can be seen from Table 6, at Lags 1 and 2, in DGDP and $\mathrm{DCO}_{2}$ Granger causality test, for the original hypothesis " $\mathrm{D}(\mathrm{GDP})$ does not Granger Cause $\mathrm{D}\left(\mathrm{CO}_{2}\right)$ " in Lag 1, P value is 0.0045 , it is considered to reject the former hypothesis that the GDP growth is the cause of increased carbon dioxide emissions. For the original hypothesis " $\mathrm{D}\left(\mathrm{CO}_{2}\right)$ does not Granger Cause $\mathrm{D}(\mathrm{GDP})$ ", $\mathrm{P}$ values are 0.5511 and 0.0967 , so it is considered to accept the original hypothesis that $\mathrm{CO}_{2}$ is not the cause of changes in GDP, and increased carbon dioxide emission is not the reason for the changes in GDP.

Table 7. Granger Causality Test results of DENE and $\mathrm{DCO}_{2}$

\begin{tabular}{cccccc}
\hline Lags: & Null Hypothesis: & Obs & F-Statistic & Prob. & Conclusion \\
\hline 1 & $\mathrm{D}\left(\mathrm{CO}_{2}\right)$ does not Granger Cause $\mathrm{D}(\mathrm{ENE})$ & 21 & 0.11223 & 0.7415 & Accept \\
& $\mathrm{D}(\mathrm{ENE})$ does not Granger Cause $\mathrm{D}\left(\mathrm{CO}_{2}\right)$ & & 0.17433 & 0.6812 & Accept \\
2 & $\mathrm{D}\left(\mathrm{CO}_{2}\right)$ does not Granger Cause $\mathrm{D}(\mathrm{ENE})$ & 20 & 3.00371 & 0.0800 & Accept \\
& $\mathrm{D}(\mathrm{ENE})$ does not Granger Cause $\mathrm{D}\left(\mathrm{CO}_{2}\right)$ & & 3.41129 & 0.0601 & Reject \\
\hline
\end{tabular}

Table 7 shows that in Lag 2, for the original hypothesis " $\mathrm{D}(\mathrm{ENE})$ does not Granger Cause $\mathrm{D}\left(\mathrm{CO}_{2}\right)$ ", the $\mathrm{P}$ value is 0.0601 , so it's considered to accept the original hypothesis that the increase in energy consumption is the reason for the increase of carbon dioxide emissions. For the original hypothesis $\mathrm{D}\left(\mathrm{CO}_{2}\right)$ does not Granger Cause D(ENE)", the P values are 0.7415 and 0.0800 , respectively, and therefore it's considered to accept the original hypothesis that the increase in carbon dioxide emissions is not the reason for the increase in energy consumption.

\section{Conclusion}

Through the analysis of time series from1990 to 2012, it can be seen that GDP growth is the cause of the 
increase in energy consumption, while increased energy consumption is not the cause of GDP growth; GDP growth can impact directly the increase in carbon dioxide emissions, while the increase in carbon dioxide emissions is not does not affect the GDP growth; increased energy consumption can cause the increase in carbon dioxide, and the increase in energy consumption can result in the increase of carbon dioxide emissions, while the increase in carbon dioxide emissions is not the cause of the increase in energy consumption.

Therefore, in theory, we can conclude that economic growth should not be based on the increased consumption of fossil energy and from carbon dioxide emissions, which consequently reduces greenhouse gas emissions.

\section{References}

Government of Mongolia. (2011). Fourth National Report: Millennium Development Goals Implementation. Mongolia.

Batjargal, Z., Mijiddorj, R., \& Ulziisaihan. V. (1998). Climate change and sustainable development problem. Ecology and sustainable development, Ulaanbaatar, 2, 120-140.

Sun, J. S. (2005). Econometrics tutorial. Beijing, Tsinghua University Press.

Dickey, D. A., \& Fuller, W. A. (1979). Distribution of the estimators for autoregressive time series with a unit root. Journal of the American Statistical Association, 74(3), 427-431

Dan, H. (2002) Data analysis and application of Eviews. Beijing, China Statistical Press.

\section{Copyrights}

Copyright for this article is retained by the author(s), with first publication rights granted to the journal.

This is an open-access article distributed under the terms and conditions of the Creative Commons Attribution license (http://creativecommons.org/licenses/by/3.0/). 